\title{
Identification, synthesis and SAR of amino substituted pyrido[3,2b]pyrazinones as potent and selective PDE5 inhibitors
}

\author{
Dafydd R. Owen ${ }^{a}$, John K. Walker ${ }^{\text {b,* }}$, E. Jon Jacobsen ${ }^{b}$, John N. Freskos ${ }^{\text {b }}$, Robert O. Hughes ${ }^{\mathrm{b}}$, \\ David L. Brown ${ }^{\mathrm{b}}$, Andrew S. Bell ${ }^{\mathrm{a}}$, David G. Brown ${ }^{\mathrm{a}}$, Christopher Phillips ${ }^{\mathrm{a}}$, Brent V. Mischke ${ }^{\mathrm{b}}$, \\ John M. Molyneaux ${ }^{\mathrm{b}}$, Yvette M. Fobian ${ }^{\mathrm{b}}$, Steve E. Heasley ${ }^{\mathrm{b}}$, Joseph B. Moon ${ }^{\mathrm{b}}$, William C. Stallings ${ }^{\mathrm{b}}$, \\ D. Joseph Rogier $^{b}$, David N. A. Fox ${ }^{a}$, Michael J. Palmer ${ }^{a}$, Tracy Ringer ${ }^{a}$, Margarita Rodriquez-Lens ${ }^{a}$, \\ Jerry W. Cubbage ${ }^{\mathrm{b}}$, Radhika M. Blevis-Bal ${ }^{\mathrm{b}}$, Alan G. Benson ${ }^{\mathrm{b}}$, Brad A. Acker ${ }^{\mathrm{b}}$, Todd M. Maddux ${ }^{\mathrm{b}}$, \\ Michael B. Tollefson ${ }^{\mathrm{b}}$, Brian R. Bond ${ }^{\mathrm{c}}$, Alan MacInnes ${ }^{\mathrm{c}}$, Yung $\mathrm{Yu}^{\mathrm{c}}$ \\ ${ }^{a}$ Department of Chemistry, Pfizer Global Research and Development, Ramsgate Road, Sandwich, Kent CT13 9NJ, UK \\ ${ }^{\mathrm{b}}$ Department of Chemistry, Pfizer Global Research and Development, Chesterfield Parkway West, St. Louis, MO 63017, USA \\ ${ }^{\mathrm{c}}$ Department of Biology, Pfizer Global Research and Development, Chesterfield Parkway West, St. Louis, MO 63017, USA
}

\section{A R T I C L E I N F O}

\section{Article history:}

Received 8 May 2009

Revised 29 May 2009

Accepted 2 June 2009

Available online 6 June 2009

\begin{abstract}
A B S T R A C T
A new class of potent and selective PDE5 inhibitors is disclosed. Guided by X-ray crystallographic data optimization of an HTS lead led to the discovery of a series of 2-aryl, (N8)-alkyl substituted-6-aminosubstituted pyrido[3,2b]pyrazinones which show potent inhibition of the PDE5 enzyme. Synthetic details and some structure-activity relationships are also presented.
\end{abstract}

(c) 2009 Elsevier Ltd. All rights reserved.

\section{Keywords:}

PDE5

PDE6

PDE11

Inhibitors

Cyclic guanidine monophosphate (cGMP) is a second messenger for nitric oxide and atrial natriuretic peptide. Increasing levels of cGMP activates protein kinase $G$ which through phosphorylation of other downstream proteins promotes vasorelaxation. Phosphodiesterase type 5 (PDE5) is widely expressed in smooth muscle, lung, kidney and platelets and plays a major role in regulating intracellular levels of cGMP through degradation of cGMP to the inactive $5^{\prime}$-GMP. ${ }^{1}$ For this reason, PDE5 inhibitors were originally studied as potential anti-hypertensive or antianginal agents. The discovery of the potent PDE5 inhibitor sildenafil (Viagra ${ }^{\circledR}$ ), Figure 1 , led to breakthrough therapies for male erectile dysfunction and has spurred development of additional PDE5 agents such as vardenafil (Levitra ${ }^{\circledR}$ ) and tadalafil (Cialis ${ }^{\circledR}$ ). ${ }^{2,3}$ More recently, sildenafil was approved for the treatment of pulmonary hypertension $\left(\right.$ Revatio $\left.{ }^{\circledR}\right)$ further illustrating the potential of PDE5 inhibitors as therapeutic agents. ${ }^{4}$

As the potential therapeutic uses of PDE5 inhibitors grow there is an increasing need to develop new classes of inhibitors more suitable for chronic usage. One liability of the current marketed

\footnotetext{
* Corresponding author. Tel.: +1 6362478895 .

E-mail address: john.k.walker@pfizer.com (J.K. Walker).
}<smiles>CCCc1nn(C)c2c(=O)[nH]c(-c3cc(S(=O)(=O)N4CCN(C)CC4)ccc3OCC)nc12</smiles><smiles>CCCn1ccc(=O)c2c(N)nc(-c3ccccc3)cc21</smiles>

Figure 1.

class of inhibitors is a less than ideal selectivity profile against other members of the PDE family. ${ }^{5-7}$

As part of our on-going effort ${ }^{8}$ to identify potent, selective, and long-acting PDE5 inhibitors, a high-throughput screen of the Pfizer compound file was initiated. The screen yielded the phenyl substituted quinolin-4-one derivative $\mathbf{1}$ (Fig. 1) as a potent PDE-5 inhibitor $\left(\mathrm{IC}_{50}=51 \mathrm{nM}\right)$ but with poor selectivity for PDE6 $\left(\mathrm{IC}_{50}=6 \mathrm{nM}\right)$.

To facilitate further optimization of this lead, we obtained an Xray crystal structure of 1 bound in the active site of $\mathrm{PDE}^{9}$ (see Fig. 2). A comparison between $\mathbf{1}$ and sildenafil in the active site revealed the $n$-propyl group of $\mathbf{1}$ fits into the lipophilic pocket 


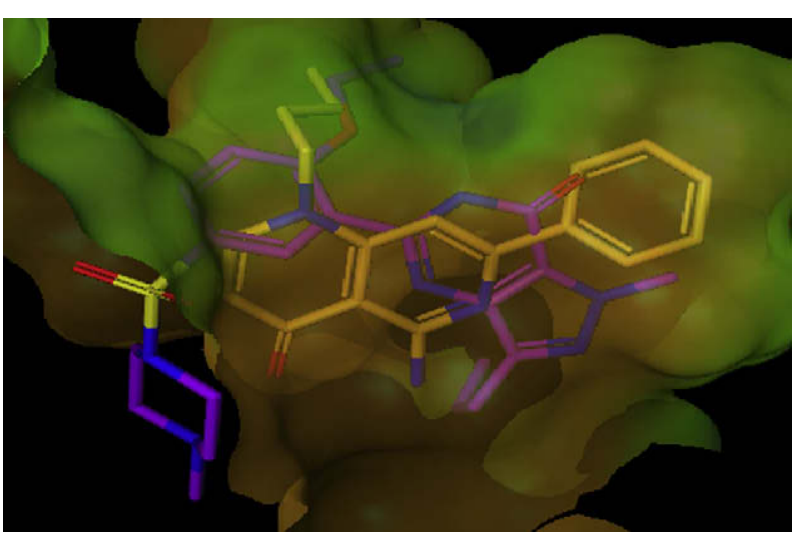

Figure 2. Overlay of co-crystal structure for compound $\mathbf{1}$ (orange) and sildenafil (purple) in the active site.

occupied by the ethoxy group of sildenafil. Additionally, the phenyl ring of 1 pointed into a deep lipophilic pocket not occupied by sildenafil. Finally, inspection of the crystal structure revealed that the solvent exposed space, occupied by the sulfonylpiperazine group in sildenafil, was unoccupied by 1 suggesting a potential handle for physical property and PK modulation via the incorporation of polar functionality (Fig. 3).

Our enthusiasm for $\mathbf{1}$ was tempered, however, by concerns over the drug ability of the quinolin-4-one scaffold. In addition, 1 was plagued by an inefficient and lengthy synthesis which presented limited handles for systematic modification. The crystal structure of 1 suggested that replacement of the quinolin-4-one system, to address these concerns, with similarly substituted 6,6 fused ring systems should be tolerated. We first explored this idea by examining a small set of related 2-quinolones represented by 2 (Fig. 2). We were pleased to find compound $\mathbf{2}$ maintained activity on PDE5 $\left(\mathrm{IC}_{50}=25 \mathrm{nM}\right)$ and, more importantly, demonstrated some selectivity against PDE6 (sixfold). While encouraged by this result we also viewed the 2-quinolone scaffold to be a non-optimal template suffering from high lipophilicity and the presence of a potential Michael acceptor. Building off compound 2, we next turned our attention to the dihydropyrazinone core exemplified by compound 3. Gratifyingly, 3, which has a $\operatorname{lower} \log D$ and lacks the Michael acceptor, also maintained similar potency and selectivity to $\mathbf{2}$ (PDE5 $\mathrm{IC}_{50}=2 \mathrm{nM}$, PDE6 $\mathrm{IC}_{50}=20 \mathrm{nM}$ ); however the aqueous solubility of this series was still poor. Similar to what we observed in the analysis of $\mathbf{1}$ the crystal structure of $\mathbf{3}$ (not shown) bound to PDE5 suggested that the lower left region of the molecule pointed to solvent and would allow for the incorporation of an ionizable center to potentially improve solubility. Of the 6, 6 ring systems which we envisioned capable of projecting substituents toward<smiles>COc1ccc(Cn2c(=O)ccc3ccc(-c4ccncc4)cc32)cc1</smiles>

2

PDE5 $\mathrm{IC}_{50}=25 \mathrm{nM}$ PDE6 IC $50=150 \mathrm{nM}$ PDE11 IC $50=41 \mathrm{nM}$<smiles>CCCCCN1C(=O)CN(C)c2ncc(-c3ccc(F)c(F)c3)cc21</smiles>

3

PDE5 $\mathrm{IC}_{50}=43 \mathrm{nM}$

PDE6 $\mathrm{IC}_{50}=1160 \mathrm{nM}$

PDE11 IC $50=>2000 \mathrm{nM}$
Figure 3. Structure and PDE data for a set of rationally designed inhibitors.

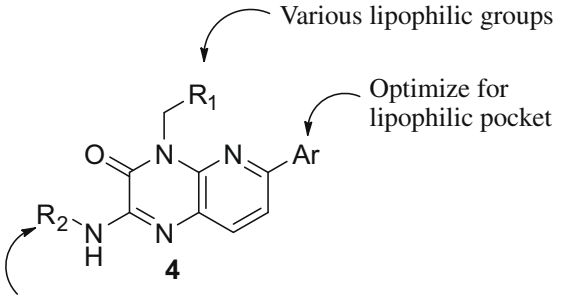

Build out towards solvent front

Figure 4. Representative pyridopyrazinone scaffold to serve as the template for our analog program.

solvent, the amino-pyrido[3,2b]pyrazinone (Fig. 4) was particularly attractive as a starting point for further optimization.

In addition to allowing for the incorporation of a third substituent, the pyrazinones could be obtained through a flexible synthesis that would allow for rapid generation of SAR for each of the three regions. Furthermore, compound $\mathbf{4}$ would strike a good balance between decreasing lipophilicity and maintaining the same binding mode observed with the previous leads as depicted in Figure 5.

Toward these ends, we initiated efforts to prepare analogs in the pyridazinone template. Synthesis of the pyridopyrazinones was carried out according to Scheme 1 . Reaction of a primary amine

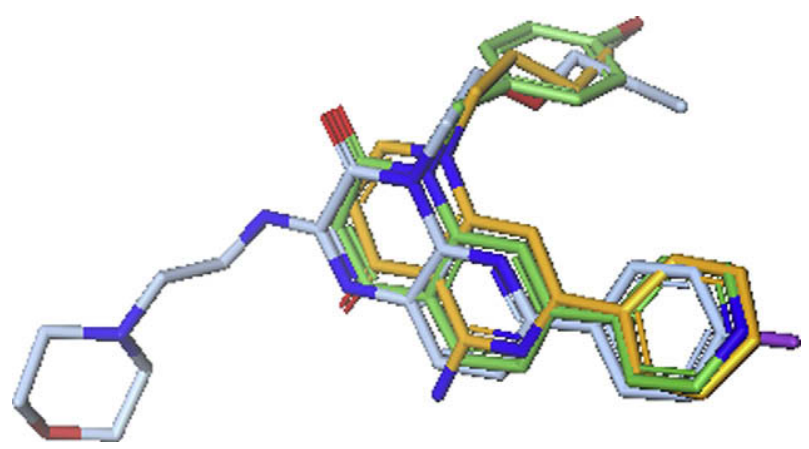

Figure 5. Overlay of co-crystal structure of compound $\mathbf{1}$ (green) with the minimized conformation of $\mathbf{3}$ (orange) and prototype pyridazinone inhibitor $\mathbf{2 2}$ (blue).<smiles>[R]CNc1nc(Cl)ccc1N</smiles><smiles>[R]Cn1c(=O)c(=O)[nH]c2ccc(Cl)nc21</smiles>

$\mathrm{d}$,<smiles>[R]Cn1c(=O)c(N[R2])nc2ccc(Cl)nc21</smiles>

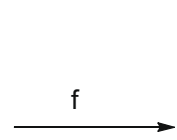<smiles>[R]Cn1c(=O)c(N[R2])nc2ccc([Se])nc21</smiles>

Scheme 1. General synthetic scheme to the pyridopyrazinone scaffold. Reagents and conditions: (a) $\mathrm{R}^{1} \mathrm{CH}_{2} \mathrm{NH}_{2}, \mathrm{Na}_{2} \mathrm{CO}_{3}, i \mathrm{PrOH}, 0-20{ }^{\circ} \mathrm{C}$; (b) $55 \mathrm{PSI} \mathrm{H}_{2}$, Raney Ni; (c) oxalic acid, $4 \mathrm{~N} \mathrm{HCl}$, reflux $16 \mathrm{~h}$; (d) oxalyl chloride, DMF, $\mathrm{CH}_{2} \mathrm{Cl}_{2}$; (e) $\mathrm{R}^{2} \mathrm{NH}_{2}, \mathrm{Et}_{3} \mathrm{~N}$, $\mathrm{CH}_{2} \mathrm{Cl}_{2}$; (f) aryl boronic acid, $\mathrm{Pd}\left(\mathrm{Ph}_{3}\right)_{4}, \mathrm{Na}_{2} \mathrm{CO}_{3}$ glyme: $\mathrm{H}_{2} \mathrm{O}(5: 1)$, reflux $24 \mathrm{~h}$. 
Table 1

Structure-activity relationships for the $\mathrm{R}^{1}$ and $\mathrm{R}^{2}$ positions<smiles>[R]Cn1c(=O)c(N[R2])nc2ccc(-c3ccc(F)c([X])c3)nc21</smiles>

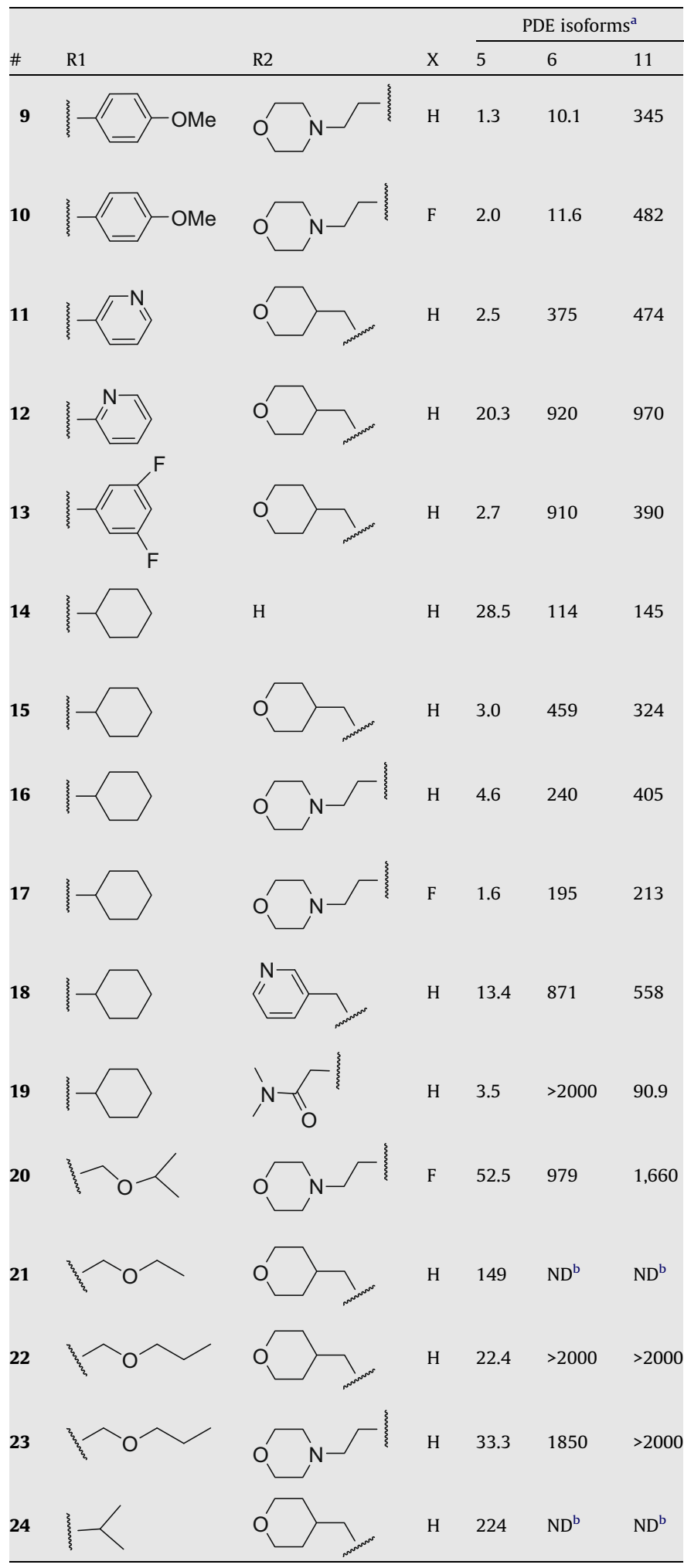

a Assay protocols can be found in Ref. 10 IC $_{50}$ values are reported in nM.

b ND; Not Determined. with 2,6-dichloro-3-nitropyridine (5) occurred selectively at the 2position and gave amino-substituted pyridine $\mathbf{6}$. Reduction of the nitro group followed by reaction with oxalic acid/ $\mathrm{HCl}$ gave rise to the intermediate dione $\mathbf{7}$. In turn, $\mathbf{7}$ was exposed to oxalyl chloride in the presence of DMF to give a chloroimidate intermediate which upon exposure to either a primary or secondary amine under mildly basic conditions yielded amino-substituted pyridopyrazinone compound 8 . With both the $R^{1}$ and $R^{2}$ variables introduced the synthesis was completed by standard Suzuki coupling of $\mathbf{8}$ with various aryl boronic acids to give analogs 9-38.

Table 1 presents structure-activity relationships (SAR) of a representative set of analogs aimed at probing the breadth and scope of both the $\mathrm{R}^{1}$ and $\mathrm{R}^{2}$ substituents. Initially, we focused on analogs with the aryl substituent fixed as either the 4-fluorophenyl or 3,4difluorophenyl group. In general, the SAR highlighted that PDE5 activity was more sensitive to the nature of the $\mathrm{R}^{1}$ substituent than to the $\mathrm{R}^{2}$ substituent. We identified several analogs with PDE5 potency in the low nanomolar range with varying degrees of selectivity against PDE 6 and 11. For example, when $\mathrm{R}^{1}$ was $p$-methoxyphenyl (e.g., 9-10) we obtained potent analogs in the single digit nanomolar range with good selectivity $(\sim 100 \times)$ against PDE11 but only modest selectivity against PDE6. The 3,5-difluorophenyl analog, 13 was found to be potent against PDE5 but also shows good selectivity against both PDE6 and PDE11. Pyridyl groups were also explored with the 3-pyridyl analog, 11 being preferred as it

Table 2

Structure-activity relationships for the $\mathrm{R}^{1}$ and $\mathrm{Ar}$ positions when $\mathrm{R}^{1}$ is cyclohexylmethyl<smiles>[R2]Nc1nc2ccc([Al-])nc2n(CC2CCCCC2)c1=O</smiles>

28 PDE isoforms ${ }^{\mathrm{a}}$

${ }^{a}$ Assay protocols can be found in Ref. $10 \mathrm{IC}_{50}$ values are reported in $\mathrm{nM}$. 
Table 3

Structure-activity relationships for the $\mathrm{R}^{2}$ and Ar positions when $\mathrm{R}^{1}$ is $n$-propylethoxy<smiles>[R2]Nc1nc2ccc([Al])nc2n(CCOCCC)c1=O</smiles>

32 PDE isoforms $\mathrm{s}^{\mathrm{a}}$

a Assay protocols can be found in Ref. 10 . $\mathrm{IC}_{50}$ values are reported in $\mathrm{nM}$. b ND; not determined.

was found to be more active and show greater sparing of PDE6 and PDE11 compared to 2-pyridyl analog 12.

We also explored the saturated cyclohexyl ring which generally gave potent analogs (e.g., 15-17) with good (>100×) selectivity for PDE6 and PDE11. We also observed some impact on activity and/or selectivity due to the nature of $R^{2}$ substituent (e.g., 18-19). When $\mathrm{R}^{1}$ was a simple alkyl group or alkyl ether a drop in PDE5 potency was observed which was also accompanied by an equal or greater loss in PDE6 and PDE11 activity. The chain length proved critical for activity. The ethoxyisopropyl analog, 20, and ethoxyethyl ana$\log , 21$, both exhibit only modest inhibition of PDE5. However, when the chain was lengthened by one atom to ethoxypropyl, a nearly sixfold improvement in activity, relative to $\mathbf{2 1}$, was observed with only minimal or no increase in either PDE6 or PDE11 activity (e.g., 22 and 23).

We next probed the SAR around the aryl substituent. We elected to focus on the scaffolds where $R^{1}$ was fixed as either the cyclohexyl or ethoxypropyl group. Table 2 summarizes the SAR observed in the template where $\mathrm{R}^{1}$ was cyclohexyl. Within this series PDE5 potency was found to be relatively unaffected by the aryl group but selectivity was found to be negatively impacted. The 4-methoxypyridyl group was found to be optimal in terms of PDE5 potency (e.g., 27-29) yielding a number of analogs in the sub-nanomolar range. Unfortunately, selectivity falls off especially for PDE11 which was found to be significantly diminished in this series. Additionally, these compounds suffered from poor aqueous solubility. For example, the aqueous solubility of $\mathbf{2 9}$ was found to be $<3 \mu \mathrm{M}$, at $\mathrm{pH} 7.4$.

The results for when $\mathrm{R}^{1}$ was ethoxypropyl are summarized in Table 3. In general, these analogs tended to be less potent $(\sim 5-$ 10 -fold) than their corresponding cyclohexyl variants found in Table 2 (see for e.g., $\mathbf{2 9}$ vs $\mathbf{3 5}$ for a comparison). We also noted a similar trend with respect to the 2-methoxypyridine substituent which was again found to be optimal with regard to PDE5 potency as highlighted by examples 34-36. More importantly, however, these compounds demonstrated good selectivity against PDE6 $(>100 \times)$ and excellent selectivity against PDE11 $(>600 \times)$. Poor solubility was still as issue with this series as 36 was measured to have a solubility of $4.6 \mu \mathrm{M}$, at pH 7.4. Finally, as a representative example for the series, we also assessed the rat ${ }^{11,12}$ pharmacokinetic (PK) profile of 36. This compound exhibited high clearance $(67.6 \mathrm{ml} / \mathrm{min} / \mathrm{kg})$ resulting in a modest half-life $(\sim 3 \mathrm{~h})$ indicating further refinement of the template would be required. Efforts to further optimize this scaffold to improve the PK properties, as well as the physical-chemical properties, will be discussed in the following Letter of this journal.

In conclusion, we report the discovery of a novel series of 2amino substituted pyrido[3,2b]pyrazinone analogs that show potent and selective inhibition of PDE5. Starting from a novel lead, $\mathbf{1}$, identified in a high-throughput screen and relying heavily on $\mathrm{X}$-ray crystal structures we developed the pyridopyrazinone template 4 through a series of lead-hopping exercises. We further optimized the template to identify a handful of potent and selective analogs.

\section{References and notes}

1. (a) Beavo, J. A. Physiol. Rev. 1995, 75, 725; (b) Corbin, J. D.; Francis, S. H. J. Biol. Chem. 1999, 274, 13729.

2. Haning, H.; Niewöhner, U.; Bischoff, E. Prog. Med. Chem. 2003, 41, 249.

3. Stamford, A. W. Annu. Rep. Med. Chem. 2002, 37, 53.

4. Ghofrani, H. A.; Osterloh, I. H.; Grimminger, F. Nat. Rev. Drug Disc. 2006, 5, 689.

5. (a) Pomara, G.; Morelli, G. Int. J. Impot. Res. 2005, 17, 385; (b) Pomara, G.; Morelli, G.; Canale, D.; Turchi, P.; Caglieresi, C.; Liguori, G.; Selli, C.; Macchia, E.; Martino, E.; Frencesca, F. Fertil. Steril. 2007, 88, 860.

6. (a) Goldstein, I.; Lue, T. F.; Padma-Nathan, H.; Rosen, R. C.; Steers, W. D.; Wicker, P. A. N. Eng. J. Med. 1998, 338, 1397; (b) Cote, R. H. Int. J. Impot. Res. 2004(16), S28.

7. Manallack, D. T.; Hughes, R. A.; Thompson, P. E. J. Med. Chem. 2005, 48, 3449.

8. (a) Palmer, M. J.; Bell, A. S.; Fox, D. N.; Brown, D. G. Curr. Top. Med. Chem. 2007, 7, 405; (b) Heasley, S. E.; Jacobsen, E. J.; Walker, J. K.; Hughes, R. O.; Freskos, J.; Brown, D. L.; Fobian, Y. M.; Owen, D.; Mischke, B. V.; Tollefson, M. B.; Molyneaux, J.; Blevis-Bal, R.; Maddux, T.; Brown, D. G.; Moon, J. B.; Phillips, C.; Rogier, D. J.; Benson, A. Abstracts of Papers, 236th National Meeting of the American Chemical Society, Philadelphia, PA, Aug 17-21, 2008; American Chemical Society: Washington, DC, 2008; MEDI-397.

9. The coordinates have been deposited in the PDB under accession code 3HDZ.

10. Brown, D. L.; Owen, D. R.; Phillips, C.; Palmer, M. J.; Bell, A. S.; Freskos, J. N.; Fobian, Y. M.; Walker. J. K.; Hughes, R.; Jacobsen, E. J.; Tollefson, M. B.; Brown, D. G.; Mischke, B. V.; Molyneaux, J. M.PCTWO 07/020521.

11. The Pfizer Institutional Animal Care and Use Committee reviewed and approved the animal use in these studies. The animal care and use program is fully accredited by the Association for Assessment and Accreditation of Laboratory Animal Care, International.

12. PK experiments were conducted in Sprague Dawley rats under the following conditions; IV: 2 mpk ( $n=3$ ) vehicle: $70 \%$ PEG400/20\% $0.05 \mathrm{M}$ citrate buffer $10 \%$ ethanol, $\mathrm{pH} 5$; PO: $2 \mathrm{mpk}(n=3)$ vehicle: $0.5 \%$ methylcellulose $/ 0.1 \%$ Tween 80 in $50 \mathrm{nM}$ citric acid, $\mathrm{pH} 5$. 